\title{
Newly Recognised or New Blood Transfusion Transmitted Infections. Challenges, to be Faced by Clinicians, Transfusion Experts, Which Certainly Needs Refreshed Blood Banking Skills and Clinical Approaches
}

\author{
Miklos Udvardy* \\ Professor Emeritus, Debrecen Medical University, Faculty of Medicine, Department of Hematology, Hungary
}

Received: June 06, 2018; Published: June 19, 2018

*Corresponding author: Miklos Udvardy, Professor Emeritus, Debrecen Medical University, Faculty of Medicine, Department of Hematology,4032 Debrecen, Nagyerdei krt 98, Hungary

\section{Abstract}

Preparative and clinical transfusiology and transfusion, a majestic part of clinical medicine saved and saves the life of hundred millions. However, times and pathogens are continously and rather quickly changig, so during the last decade many not only egzotic new or newly recognised pathogens and diseases were showed up, and some of them (e.g. Zyka virus, Hepatitis E vrus, Ebola, etc.) can also be transmitted by blood or blood component transfusions, and in some instances they escape from standard screening and inactivation procedures. Hereby we try to focus and draw attention to some of these potentially pathogen new bloodborne microbiological agents, and along with this we try to emphasize the significance of application of updated next generation screenig and inactivation procedures. Interestingly a recent British trial, based on large population data showed some evidence of slight increase of non Hodgkin lymphoma incidence in patients with multiple previous transfusions.

Our approach is purely a clinician one (clinical hematologist), bedside oriented. These new facts, knowledge and skills are badly needed for all of us: doctors (a broad, almost entire range of specialists), blood banking people, departments of epidemiology and also some special cohorts of patients: i.e. for the hemophiliacs and their family, who still receive plasma derived prophylactic treatment 3 times weekly. It is due time, that some especially endangered cohorts of patients and family should receive the necessary information, and go for a fully informed consent based preference, based on the advantages and hazards of particular treatment modalities.

Keywords: Newly Recognised Bloodborne Pathogens; Screening and Inactivation; Refreshing Transfusion Transmitted Clinical Settings; Haemodialysis; Cryoprecipitate; Propionibacterium, Staphylococcus, Bacillus Enterococcus; Ixodus Scapularis; Ribavirin Treatment

Abbreviations: AIDS: Acquired Immundeficiency Syndrome; CMV: Cytomegalo Virus; ELISA: Enzymatic Immunoassay; FDA: Federal Drug Administration, US; EASL: European Association Of Liver Diseases; HIV: Human Immunodeficiency Virus; HEV: Hepatitis E Virus; NAT: Nucleic Acid Based Test; PCR: Polymerase Chain Reaction ; TTP/HUS:Thrombotic Thrombocytopenic Purpura/Haemolytic Uraemic Syndrome; TT virus. (torque teno): Transfusion Transmitted Virus Species; USUV: APathogen Resembling West-Nile Virus

\section{Introduction}

Preparative, as well clinical transfusiology was always and remains one of the greatest and highly respectable, important achievement of clinical medicine, saving the lifes of many millions directly, and rendering possibility for haemodialysis, TTP/HUS therapies, immunoglobulin supplements, etc. However, during the last one and half decade new pathogens appeared unexpedly on the scene, many of them were newly recognised, or just reconsidered that they are not limited to egzotic areas only, but can appear way up North or West moving into more developed countries. This cer tainly needs new epidemiological data analysis, donor screening, and new generation of inactivation procedures, many of them still to be developed. But most of all, these informations should be built into bedside clinicians approach, refreshed knowledge and skills are badly needed on clinical grounds, too. This paper has been prepared by a clinical hematologist and transplant expert, and as such really feels the demand to adhere to this bulk of new data in everyday approach to transfusion and their influence on clinical practice. 


\section{Bloodborne or Transfusion Transmitted Infections}

History:Transfusion safety had been challenged in France, in the late 1980s, when previously cryoprecipitate (gained from 3-4 donors) based hemophilia treatment [1-3] was switched to plasma derived concentrates (gained from hundreds or thousends of donors per batch). These multidonor based plasma derived factor derivatives proved to be very efficient bleedingwise, however, the early period shortcomings of donor screening and inactivation resulted in a large tragical series of HIV-AIDS and hepatitis $C$ viral infections. These tragic events gave a push to quickly develop powerful new donor screening and inactivation procedures, including donor interviewing (sexual and traveling habits, social surroundings, previous medical history, drugs,etc.), new viral screening, including NAT methods, PCR and conforming community regulations like FDA or European regulatory agencies [1-3]. New series of inactivation methods had been implemented including heat-dry methods, solvent-detergent approach, affinity chromatography, later on nanofiltration, and switch toward as much as possible leukodepleted products, the general standard became to apply at least minimally two approach for inactivation [1-3]. These interventions resulted in much better transfusion safety prettty soon, and seemingly minimalised blood borne infections issue. As new or newly recognised agents started to spread, it became more and more evident, that the aforementioned donor safety and inactivation seems to fail in some instances $[3,4]$. Traditional methods could not stop the prions, too, but thris paper does not deal with prion issue, as it is not a cenventional pathogen.

\section{New Infectious Agent Data and New Approach to Trans- fusion Transmitted Diseases}

Bacteria: Low grade bacterial transmission during transfusion is the general rule with packed red blood cells. even if it is considered almost zero chance, the average number is 1 really disease inducible pathogen transmission per 38500 packed red blood cells bag. Platelet is a different issue, due to differences in heat inactivation procedures and short storage time, so the average number of pathogenic (clinically evident) bacterial transmission is 1 pro 2000-5000 units of platelets [5-9]. If you consider that the average number of platelet units might be 4-10 in oncohematology or bone marrow transplanted, immunosuppressed patients, this danger is still quite high, and might claim for preventory steps at bedside, including avoiding of unnecessary platelet supplements [8,9].Geographical differences are quite substantial in bacterial transmission data and danger regarding continents, regions or particular countries. North America, Europe: Yersinia,Proteus, Pseudomonas, Escherichia, Klebsiella, Acinetobacter, Serratia, Gram-positives: Propionibacterium, Staphylococcus, Bacillus Enterococcus occasionally. Japan: most frequent contamination Propionibacterium acnes. Netherlands: interestingly coagulase-negative staphylococci is the most common.Yershinia Enterocolitica can tolerate lower temperatures quite well, so may be persistent even after longer storage periods [5-9]. Bacterial transmission can be important issue in interventions with unusually large transfusion need (liver transplantation, etc) so it should receive special care and attention [10].
Protozoons: Malaria: for the time beeing the estimated number of malariac patients should be at least 300 Million at our Globe. It is a well known tick-mosquito born infection, but blood transfusion might also transmit this disease in endemic areas, i.e Benin when donors malaria falciparum frequency might even reach $30 \%$ etc.). Interestingly malaria transmission by transfusion should also be considered in non-endemic areas, like Spain [11,12]. FDA do recommends donor screening, and caranteens all for one year, who lives or travelled to malaria areas recently. Of course leukodepletion does not help in malaria trasmission prevention $[8,11]$. Babesiosis: similar to malaria, regarding tickborne spread (ixodus scapularis) and red blood cell involvement, but it runs more dangerous and complex clinical course then malaria. No doubt, it can be transmitted with packed red blood cells, leukodepletion is useless in this respect. Severe cases one may see hemolysis, low platelet counts, and fatals cases are not so uncommon. FDA registered 70 transfusion related babesiosis cases in the US, with 10 fatalities. 9 of 10 fatal cases has been transmitted during the last three years, which, is a serious warning.Babesiosis tranfusion transmission is more likely with AIDS, immunosuppressed patients or even after splenectomy [2,13].Trypanosoma cruzi: Chagas disease: acute or chronic lymphadenopathy, splenomegaly. Endemic in some parts of Africa and Mexico. FDA registered 7 transfusion transmitted Chagas cases, donor screening needs special ELISA [1,9].

New Viral Transmisssion Data: Hepatitis A és E virus: both virus spreads basically on feco-oral route. Most E virus infection comes form pork products (raw or cooked). But in fact both virus can be acquired via transfusion, as well. Their common property is the resistance to plasma component fractionation and solvent-detergent inactivation procedures. This paper focus on the less known hepatitis E virus. Subtype G1 and G2 typical feco-oral pathogen in developing countries, while G3 and G4E might be considered as zoonosis linked to pork meat products. To some surprise, hepatitis $\mathrm{E}$ viral infection is a frequent cause of acute viral hepatitis even the UK[14]. It is of critical importance that E virus might be transfusion transmitted both in endemic and non-endemic regions, and now it is strongly recommended to perform routine $\mathrm{E}$ virus donor screening [15], a simple E virus antibody measurement does not seem to be enough for this purpose. E viral hepatitis might be mild or subclinical. New EASL guideline clearly states, that E viral heaptitis might also be the leading cause of acute hepatitis in some of good GDP countries, as well. It may also cause renal, neurological, hematological alterations and complications $[15,16]$. EASL recommends well cooked pork foods for immunosuppressed patients and compulsory hepatitis E virus NAT screening of donors[16,17]. It does not matter if they visited endemic regions or not. As vidarabin seems to be powerful and capable to get rid of hepatitis E virus disease, all these knowledge, precautions, and special diagnostics possess crucial importance.

Zika (Zyka) and Ebola Virus: Much frightened pathogens, both can be transmitted by transfusion. FDA implemented Zika donor screening quite recently (in endagered donor population) and the fith donor proved to be positive [18]. 
West-Nile virus (and USUV): West Nile virus is a typical tick-mosquito borne disease, but can also be transmitted via blood transfusion, too. Symptoms frequently mild, but some meningoencephalitis cases have been reported mainly in immunosuppressed patients. It belongs to flavivirus strains, and can be detected with special NAT assay. If FDA register NAT positivity keeps the donor for 120 days away, than repeats the NAT $[19,20]$. USUV virus shares some properties with West nile virus, and shows cross reaction with West-Nile vírus NAT or PCR. It belongs also to flavivirus family. It is present in south and Central Europe, including Germany. Can be transfusion transmitted disease. Some USUV encephalitis cases were reported more recently in Italy [19,20].

TT Virus: name is not related to transfusion transmitted virus, but to the name of the first patients with the disease (Torque Teno). Its role is suggested but not completely proved in some chronic liver diseases, and oncologic entitites. TT frequency is $17 \%$ in liver transplanted patients, and even more, $25 \%$ in cirrhotics.There are some data, on TT viruses, that they can accelerate liver disorders, increase the susceptibility to B viral coinfections. Some authors presume, that cryptogenic cirrhosis might be TT related. Few data suppert TT role in oral cavity malignant tumors [21,22].

SEN Virus: DNA vírus, which has 30\% positívity in operated plus transfused patients, while only $3 \%$ in operated, nontransfused population. Their pathologic role in chronic liver disase seems uncertain. Nevertheless, it may reduce the efficiency of ribavirin treatment based antiV virus protocols [23].Dengue and chikungunya virusBoth are endemic in Latin-America, can be transfusion transmitted ( 45 documented case), but transfusion transmission is limited to endemic areas only $[2,3]$.

Parvo B19: A classical dog virus, usually does not harm human beings. But if viremia reaches high level it may cause aplastic anemia or pure red aplasia as the the virus is not lipid coated, solvent detergent or methylene blue inactivation is not able to get rid of their presence in transfused blood or components. It may also cause fetal hydrops, so anti D immunoglobulins should be carefully selected considering this[1-4].

Cytomegalovirus: means a severe threat and danger (reactivation) in deeply immunsuppressed or transplanted patients. It is linked to leukocytes. leukodepletion alone does provide cytomegaloviral safety, donor seronegativity is also a must to achieve complete safety [24].

\section{Revision and New Standards of Donor Screening Diag- nostics and Inactivation Procedures}

Donor Selectioin, Interview: continuous refreshments of life style, diseases including newly described infections, tourism, sexual, eating, social habits., Anything which might be even a little bit relevant should be in depth analysed, good to be keen on following different FDA attitudes and steps regarding transfusion safety [1-3].

'Donor Diagnostics: old standards should not be ommitted, buti $\mathrm{n}$ addition to that to develop updated, valid, efficient technologies in diagnosis of new or potential pathogens, including mainly hepatitis E, parvo and cytomegalo sensitivity, TT/SEN virus detec- tion are essential along with West-Nile/USUV in all (?), but malaria, babesiosis, Zyka, dengue also in selected cases [1-5,9,25].

Leukodepletion: A generally accepted principle, so it is important to enforce and speed up to became a standard general approach in all cases.

a) Virus/Pathogen Inactivation: First and second generation inactivation procedures remain still extremely important, but the implementation of new methods has to be done (many of them still to be developed) quickly. WHO (2016) recommended new generation Mirasol, Theraflex and Intercept methods are using chemical effects combiningUV applications. The latter three methods are licensed in Europe [2, 4, 13, 17, 25,26].Plasma derived factor concentrates, prepared from a large number of donors need special attention, inactivation certainly needs more then two interventions, as a new standard $[9,25]$.

b) E. Transfusion and Oncology: Transfusion induced cancer is a strange, astonishing new idea, interpretation certainly needs great caution, and should not interfere with life saving transfusion activites.A UK paper was published quite recently. This compared the long term outcome and cancer incidence of 1,3 Million women without tranfusion history, as opposed to 11274 females reeciving transfusions. None of the patients of the to group had previous cancer or precancerous condition to their best knowledge. Followup was divided into first and second five years observation period.They did not pay too much attention to the first five year period, considering viruses, and liver cancer indirect relationship, and unknown preexisting precancerous conditions. Surprisingly more cancer cases were found in the transfused cohort during the second five years, liver cancer risk was 1,45 , non-Hodgkin lymphoma relative risk (including multiple myeloma) proved to be 1,74 . They found the same correlation if only hip replacement surgery cases wer analysed [27].

\section{Discussion andRecommendations}

Clinical transfusiology and transfusion still remains one of the greatest achievements in clinical medicine.The historical boom of plasma derived clotting factor transmitted AIDS and hepatitis C in turn resulted in major stepforwards and advances in the safety of transusion, blood component disease diagnostics, donor screening and inactivation procedures. Following this efforts clinical transfusiology - using new standards - soon regained safety, even on large scales.But the last 10-15 years brought up quite a lot of new challenges (travelling habits, more immunosuppressed, transplanted patients). But other type of new challenges are quickly entering the scene: new or newly recognised pathogens, previously limited to egzotic region but spreading into North and West, which are at least in part can be transmitted by transfusions, too.These new pathogens induced disease are more and more well described, better known, and no doubt their clinical importance was (and still is) clearly underestimated (Hepatitis E, etc). They can sometimes move from endemic to non-endemic region in a surprisingly speedy fashion.Probably the most important thing is to increase clinicians, bedside doctors awareness, to diagnose and adequately treat these conditions. This is especially true for doctors taking care for im- 
munosuppressed patients. Also to reduce the numbers of unnecessary transfusions, try to avoid multiple donor (factor) derivatives, if a synthetic compund is safely available. A new training of of the medical staff concerning needle stick incidental injuries needs to be tailored to new standards.Informed consent of the patients should be restructured accordingly, especially, when there are alternative treatment modalities available (i.e. plasma derived factors versus synthetic compounds).Blood banking has to face and solve new challenges in diagnostics and inactivation as soon as possible, and strive for continuos update.

\section{References}

1. Florian B,Casteli D, Marincola F, Roger Y Dodd, Christian Brander (2007) Transfusion transmitted infections. J Transfusional Medicine 8: 25-32.

2. Ainley LI, Hewitt PE (2018) Haematology patients and the risk of transfusion transmitted infection. Br J Haematol 180(4): 473-483.

3. Shander A, Lobel GP, Javidroozi M (2016) Transfusion practices and infectious risks. Expert Rev Hematol. 9(6): 597-605.

4. Juhl D, Hennig H (2018) Parvovirus B19: What Is the Relevance in Transfusion Medicine? Front Med (Lausanne) 15: 4-11.

5. Perez P, Salmi LR, Folléa G, Schmit JL, De Barbeyrac B, et al. (2001) Determinants of transfusion-associated bacterial contamination: results of the French BACTHEM Case-Control Study. Transfusion 41(7): 862866.

6. Kuehnert MJ, Roth VR, Haley NR, Gregory KR, Elder KV, et al. (2001) Transfusion-transmitted bacterial infection in the United States, 1998 through 2000. Transfusion 41(12): 1493-1497.

7. Vasconcelos E, Seghatchian J (2004) Bacterial contamination in blood components and preventative strategies: an overview. Transfus Apher Sci 31(2): 155-161.

8. Blajchman MA, Goldman M (2001) Bacterial contamination of platelet concentrates: incidence, significance, and prevention. Semin Hematol 38: 20-25.

9. Pekrul I, Wittmann G, Möhnle P (2018) Novel aspects of the guidelines for hemotherapy 2017 Implications for anesthesiology. Anaesthesist 67(1): 56-60

10. Nemes B, Gelley F, Dabasi E, Gámán G, Fehérvári I, et al. (2015) Bacterial infection after orthotopic liver transplantation Orv Hetil 156(34): 13661382 .

11. Velasco E, Gomez Barroso D, Varela C, Oliva Diaz, Rosa Cano (2017) Nonimported malaria in non-endemic countries: a review of cases in Spain. Malaria J 29: 260-265.

12. He M, Wang J, Chen L, Liu J, Zeng P (2017) The Impact of Emerging Infectious Diseases on Chinese Blood Safety. Transfus Med Rev 31(2): 94-101.

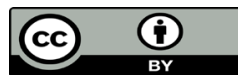

This work is licensed under Creative Commons Attribution 4.0 License

Submission Link: https://biomedres.us/submit-manuscript.php
13. Hanron AE, Billman ZP, Seilie AM, Chang M, Murphy SC (2017) Detection of Babesia microti parasites by highly sensitive 18S rRNA reverse transcription PCR. Diagn Microbiol Infect Dis 87(3): 226-228.

14. Ankcorn MJ, Tedder RS (2017) Hepatitis E: the current state of play. Transfus Med 27(2): 84-95.

15. (2018) EASL Clinical practice Guidelines on Hepatitis E virus infection. European journal of hepatology 68(6): 1256-1271.

16. Gorman J, Burke Á, O Flaherty N, (2018) Hepatitis E virus - key points for the clinical haematologist. Br J Haematol 181(5):579-589.

17. Al Sadeq DW, Majdalawieh AF, Mesleh AG, Abdalla OM, Nasrallah GK (2018) Laboratory challenges in the diagnosis of hepatitis E vírus. J Med Microbiol.

18. Goodnough LT, Marques MB (2017) Zika Vírus and Patient Blood Management. Anesth Analg 124(1): 282-289.

19. Pisani G, Cristiano K, Pupella S, Liumbruno GM (2016) West Nile Vírus in Europe and Safety of Blood Transfusion. Transfus Med Hemother 43(3): 158-167.

20. Cadar D, Maier P,Müller S, Kress J, Michael Chudy, et al. (2017) Blood donor screening for West-Nile Vírus revealed Usutu vírus infection, Germany, september 2016. Euro Surveill 22(14): 30501.

21. Kazemi MJ, Yaghobi R, Iravani Saadi M, Geramizadeh B, Moayedi J (2015) Association Between TT Vírus Infection and Cirrhosis in Liver Transplant Patients. Hepat Mon 15(9): 28370.

22. Zur Hausen H, De Villiers EM (2009) TT viruses: oncogenic or tumorsuppressive properties? Curr Top Microbiol Immunol 331: 109-116.

23. Akiba J, Umemura T, Alter HJ, Kojiro M, Tabor E (2005) SEN vírus: epidemiology and characteristics of a transfusion-transmitted vírus. Transfusion 45(7): 1084-1088.

24.Ziemann M, Thiele T (2017) Transfusion-transmitted CMV infection current knowledge and future perspectives. Transfus Med 27(4): 238248.

25. Yonemura S, Doane S, Keil S, Raymond Goodrich, Heather Pidcoke, et al. (2017) Improving the safety of whole blood-derived transfusion products with a riboflavin-based pathogen reduction technology. Blood Transfus 15(4): 357-364.

26. Drew VJ, Barro L, Seghatchian J, Burnouf T (2017) Towards pathogen inactivation of red blood cells and whole blood targeting viral DNA/RNA: design, technologies, and future prospects for developing countries. Blood Transfus 15(6): 512-521.

27. Yang TO, BJ Cairns,GK Reeves. J Green, V Beral (2017) Cancer risk amongst 21 century transfusion receipients. Million Women collaborators report. Ann Oncol 28(2): 393-399. 